\title{
Preliminary Investigation into Providing International Experience through Studying Abroad for Engineering Technology Students
}

\author{
Gary D. Steffen, Iskandar Hack \\ Indiana University-Purdue University Fort Wayne
}

\begin{abstract}
A preliminary investigation is currently ongoing to provide international experience for engineering technology students at Indiana University Purdue University Fort Wayne (IPFW). This would consist of a small group of students from the Electrical and Computer Engineering Technology Department (ECET) teaming up with a similar group of students from University of Kuala Lumpur (UKL) in Malaysia. These student groups will work on a joint design project in a classroom setting. The current plan, anticipated for the summer of 2005, will have students from IPFW going to UKL for a six week period of study and cultural exchange. While in Malaysia, the students will be staying in the UKL dormitories.
\end{abstract}

The advantage of such a program is to provide students the diversity of working on a one-on-one international project. This intense plan of study will provide students exposure of what to expect after graduation when working in a global market. Completion of the technological project will be the focus of the program. A second focus will be on the dynamics of working in a small group involving diverse members. This paper provides the preliminary investigation of challenges and achievements involved in introducing such a technology based study-abroad program.

Introduction

Expansion of university programs into international markets is not a new venture but one that seems to continue to expand with popularity. The globalizations of the world economy along with the shift of manufacturing and technology jobs to the international market place are typical reasons to investigate overseas programs. The Electrical and Computer Engineering Technology Department (ECET) at Indiana University Purdue University at Fort Wayne (IPFW) is not a stranger to this need.

Keeping pace with industrial needs is key to having an up-to-date technology based program. The ECET department at IPFW uses an Industrial Advisor Committee (IAC) as one method of tracking industrial needs. Members of the IAC, local corporate employers of ECET graduates, evaluate ECET programs and make recommendations for additional educational objectives. Over the last several years, typical recommendations have included better communication skills, English skills and analytical skills. Each of the recommendations was implemented and has led to improvements in the ECET program. More recently, recommendation was made by IAC members to have students be better prepared to work in an international market.

"Proceedings of the 2005 American Society for Engineering Education Annual Conference \& Exposition Copyright ASEE 2005, American Society for Engineering Education” 
Based on this recommendation, ECET began studying different avenues of implementing international experience into its degree programs. Malaysia seemed to be a good fit because of the author's familiarity with the country and their educational process. The author spent significant time in Malaysia, as well as, teaching for over two years in the Malaysian University system through a Purdue University sponsored program.

Overview of project

This program seeks to provide an international experience for students at Indiana University Purdue University Fort Wayne (IPFW) that is unavailable through any other means. A small group of students from the Department of Electrical and Computer Engineering Technology will team up a similar group of students from the University of Kuala Lumpur (UKL) in Malaysia and work on an assigned design project. The make up of each group will be one student from IPFW and two students from UKL. During the summer of 2005, the students from IPFW will go to UKL and stay in the dormitories with their counterparts from UKL to work on assigned projects. The teams will have approximately six weeks to work on their project. The advantage of this program is to provide students, both IPFW and UKL, with the ability to work one-on-one in an internationally diverse group for an extended period of time. Students will be expected to work on the project approximately four hours a day, Monday through Thursday each week. Weekends, including Fridays, will be used for cultural visits at various sites in Malaysia or to allow students free time to explore the country. This intense period of working on a single project will provide students good exposure of what to expect after graduation when working in an international industrial setting. Students participating in the program will be awarded four credit hours of credit for ECET 499, Special Projects in Electrical and Computer Engineering Technology. While the focus of the program will be the completion of a technological project, the depth of the projects will be kept at a moderate level. Focus will be on the dynamics of team work involving diverse group members, along with the opportunity to experience the cultural diversity of Malaysia.

\section{Background of project}

Thus far there have been three visits to University of Kuala Lumpur to investigate the likelihood of this program. During the first two visits, the headquarters of the university was initially visited in Kuala Lumpur, along with several other campuses within the system. In particular the FrenchMalaysian Institute near Bangi (about 25 miles south of Kuala Lumpur) and the BritishMalaysian Institute in Kuala Lumpur were visited. During the visits, it was determined that the program in Electrical Engineering Technology at the British Malaysian Institute is very compatible with the Electrical and Computer Engineering Technology program at IPFW. The University of Kuala Lumpur then approved the program and allocated a budget of approximately $\$ 3,000.00$ (US) for the first year. The University of Kuala Lumpur has offered students from IPFW to stay in their dormitories without charge. This is a major item to consider, since housing expenses are normally a major portion of any program such as this. Students participating in this project will be granted 4 hours of credit in ECET 499, which could be used in their plan of study as an ECET elective. The students will enroll in the course and pay their fees as they would for any college course. The students will also be responsible for their personal expenses such as meals while in Malaysia. In addition to the fees and living expenses, students are also

"Proceedings of the 2005 American Society for Engineering Education Annual Conference \& Exposition Copyright ASEE 2005, American Society for Engineering Education” 
responsible for their airfare to either Kuala Lumpur or Singapore. Students can take a train from Singapore to Kuala Lumpur. Airfares tend to be cheaper to Singapore.

The third visit led to final preparations which included the confirmation of the students living arrangements as well as the arrangement of housing on campus for both instructors. A campus twelve-passenger van and automobile will be made available to the instructors for weekend excursions with the students. A memorandum of understanding (Appendix A) has been signed between the two institutions.

Justification for project

Students at Indiana University - Purdue University Fort Wayne (IPFW) have very limited exposure to international students in comparison to students at more traditional campuses in the state. And even if there was a rather large international population at IPFW, the exposure that students would have to the foreign culture is rather limited when compared to placing the student into a foreign environment. However, when students graduate from IPFW, many go to work for corporations that have international offices or manufacturing facilities. Such corporations in the Fort Wayne area include General Electric and International Truck and Engine. Graduates that have experience working with other cultures would be extremely valuable to many corporations in the Fort Wayne area.

However these issues are not unique to the Fort Wayne community. There have been several studies regarding the need for students to have an international component added to their education. The following is from a discussion paper entitled, "Strengthening the US Government's Leadership in Promoting International Education", published by the US Department of Education on November 11, 2000 (1). It highlights the national need to provide our graduates with exposure to cultures found elsewhere in the world.

To continue to compete successfully in the global economy, play a leadership role in the world, and enhance the national security, the United States must ensure that its citizens develop a broad understanding of the world, including other languages and cultures. America's leadership also depends on building ties with those who will guide the political, cultural and economic development of their countries in the future. Our increasing engagement with other nations requires a greater awareness of cultural diversity and recognition of shared values and challenges as well as the differences between nations and peoples. Expanding our horizons will promote deeper understanding of the cultural heritage and diversity that exist within our own country.

As the world enters the twenty-first century, the practice of diplomacy is no longer confined to governments, but is actively pursued by individuals and institutions in both the public and private sectors. Increasingly, the achievement of educational, economic, political, scientific, and cultural goals requires that efforts be collaborative, crossing national borders and involving broad networks of partners. While direct contact between citizens is aided by new technologies, a sophisticated knowledge of other cultures and contexts is essential to the effective exchange of information, to promote democracy and security, achieve greater economic prosperity and increase mutual understanding.

"Proceedings of the 2005 American Society for Engineering Education Annual Conference \& Exposition Copyright ASEE 2005, American Society for Engineering Education” 
International education in the twenty-first century must acknowledge this new diversity of objectives and stakeholders, and find ways to develop to the fullest the energy, expertise and experience of all our citizens. Increased investment in international education will strengthen our nation for the future.

This study identified research and study abroad as one of the key methods to achieve the goals of internationalization of university graduates.

Overview of Malaysia

Malaysia is located in the heart of Southeast Asia. Consisting of 127,000 sq. miles $(330,200$ sq. $\mathrm{km}$ ), Malaysia is divided into two main regions: Peninsular Malaysia, which lies just south of Thailand, and East Malaysia, which can be found north of Indonesia on the island of Borneo. These two regions are divided into thirteen states and federal territories. Although East Malaysia occupies the larger portion of Malaysia's total area, it is primarily comprised of undeveloped land and jungles.

Malaysia has a combined population of over 18 million people. Because of its central location, between the Indian Ocean and the South China Sea, Malaysia has traditionally been a meeting point for traders and travelers from both the East and West. As a result, Malaysia has a multicultural and multiracial population consisting of Malays, Chinese, Indians and numerous indigenous peoples. Although Malay is the official language, English is widely spoken, especially in business, and the English language is a compulsory subject in all schools.

With such a varying ethnic composition, it is no surprise that a great diversity of religions is prevalent throughout Malaysia. Although the official religion is Islam, freedom of worship is practiced. As a result, it is common to see temples, mosques and churches within the same area.

- Ethnic Groups: 59\% Malay and other indigenous, 32\% Chinese and 9\% Indian.

- Languages: Malay (official), English, Chinese dialects, Mandarin, Hakka dialects, Cantonese, Tamil and numerous tribal languages.

- Religion: Muslim (primarily Malays), Buddhism (Chinese), Hindu (Indian), Christianity, Confucianism, Taoism and tribal religions.

Reasons for selecting Malaysia

There are many reasons that Malaysia is the ideal location for this program. The first is the diverse nature of the Malaysian population. Students participating in this program will be living in a country that has significant Malay, Chinese and Indian populations. These ethnic groups have remained distinct communities within Malaysia and can be easily accessed by the students. The second reason that Malaysia is an excellent choice for this program is the number of US companies that have manufacturing operations in the region. Such companies include Motorola, Altera, Xilinx, Texas Instruments, Seagate and Intel. The students will have an opportunity to visit a number of these facilities during their time in Malaysia. A third reason that Malaysia is a good location is the safe and secure location where students can study in a diverse environment without having major safety and security concerns. The safety of program participants is a major

"Proceedings of the 2005 American Society for Engineering Education Annual Conference \& Exposition Copyright ASEE 2005, American Society for Engineering Education” 
concern. Malaysia is a safe country; the crime rate is lower than that found in many western countries. The final reason that Malaysia is a good location for this type of program is the ability of much of the population to communicate in English. This is especially true in the Kuala Lumpur area where the students will be studying. The official language is Malay; however most of the population is fluent in English.

University of Kuala Lumpur

University of Kuala Lumpur (UniKL), Malaysia's first technical university is a private institution of higher learning licensed by the Ministry of Education and managed by Universiti Teknikal MARA Sdn. Bhd. Based on its seven specialized campuses and five faculties at the Chancellery in Kuala Lumpur, UNIKL has roots that go back well into the early years of the 1950's with the establishment of Rural Development Authority (RIDA). This was aimed to help the advancement in the standard of living for the rural communities. The establishment of UniKL is the culminating point of this dream of providing quality education for all.

The University of Kuala Lumpur is the first school in Malaysia to offer a program in Engineering Technology. They have six different campuses across Malaysia, and offer degrees in a variety of Technologies. The administrative offices are situated in the heart of Kula Lumpur. The other campuses are situated in Kuala Lumpur, Bangi, Gombak, Sepang and in the states of Kedah, and Malacca.

UniKL is a unique engineering technology university as it is a specialist technical center totally dedicated to provide students with the best education and training in various engineering technology fields. Furthermore, with the state-of-the-art training equipments and peripherals the students are equipped with adequate technical theories/concepts (know-why), specialized skills and competency (know-how) to contribute to their fullest in the workforce.

The primeval aim of the institute is to provide affordable, cost effective and quality education through continual, intellectual and social development of the students. Coupled with modern state-of-the-art facilities and taught by well-qualified lecturers, UniKL with its seven branch campuses and five faculties create a conducive and pleasant environment for learning.

Currently, the university has approximately 6500 students studying in the branch campuses in the fields of Engineering Technology. The branch campuses that make up Universiti Kuala Lumpur are British Malaysian Institute (UniKL-BMI), Malaysian French Institute (UniKL-FI), Malaysian Spanish Institute (UniKL-MSI), Malaysian Institute of Aviation Technology (UniKL-MIAT), Malaysian Institute of Chemical Engineering Technology (UniKL-MICET), Institute Infotech MARA (UniKL-IIM) and Malaysian Institute of Marine Technology (UniKL-MIMET). All these institutions were founded with the cooperation and assistance from the government of the United Kingdom, France, Spain and the United States.

\section{Student Expenses}

The major expense from the student prospective will be their airfare, but they need to also figure about $\$ 12.00$ per day for meals. The University of Kuala Lumpur is providing housing as

"Proceedings of the 2005 American Society for Engineering Education Annual Conference \& Exposition Copyright ASEE 2005, American Society for Engineering Education" 
discussed earlier in this document; however, they are not providing any meal service. There is a catering service on campus that can provide western meals for the amount discussed, or the students can opt to eat at the campus cafeteria, which is cheaper but serves mostly Malaysian food. However, meals in Malaysia are very inexpensive in most small restaurants or stalls. Students should also budget for any 'tourist type activity' that they may wish to engage in. However, most weekends will be used for the cultural visits across the country. And these visits actually are the type of activity that most people would consider tourist activities. Any type of souvenirs purchased would be at the student's expense.

Trip Budget

The major expense for this project will be for airfare for both the students and faculty. Currently, discount airfare from Fort Wayne to Kuala Lumpur is about \$1300.00, including taxes. Continuing Studies at IPFW have reserved 15 tickets, which are cancelable at this rate. There is also a need for additional tickets for the instructors. The airfare should be figured at approximately $\$ 1300$ per student, plus $\$ 1300$ for each instructor. There will also be one advance trip to Malaysia well in advance of the program to ensure proper coordination with the Malaysian institution. An additional instructor will also travel to Malaysia to aid with the start of the program. This instructor will only be in the country for about three weeks and would receive minimal pay for his/her participation with the program. However, this instructor would be working with the program coordinator/instructor to direct subsequent programs in the future, to allow for expansion of the program, or possibly take over the program at some point. The table below is an estimate of the expenses for the first year of the program.

Summary of Expenses

\begin{tabular}{|l|l|l|}
\hline Item & Cost (assuming 10 students) & Note \\
\hline Airfare for Students & $\$ 13000$ & $\$ 1300$ per student \\
\hline Airfare for Instructor & $\$ 2600$ & $\$ 1300$ for two trips \\
\hline Airfare for Assistant & $\$ 1300$ & Estimate \\
\hline Stipend for Assistant & $\$ 1000$ & $\begin{array}{l}\text { Requested by Uni-KL for } \\
\text { travel to historical-cultural } \\
\text { sites on weekends }\end{array}$ \\
\hline Cultural Travel Expenses & $\$ 1500$ & Estimated figure. \\
\hline $\begin{array}{l}\text { Additional Expenses such } \\
\text { as taxis, meals during } \\
\text { travel, travel in Malaysia } \\
\text { via train or bus }\end{array}$ & $\$ 1500$ & \\
\hline Total & $\$ 20,900$ & \\
\hline
\end{tabular}

There is no budgeted instructor's salary because the students will sign up for a four credit hour course that will provide the stipend for the instructor. However, because this program is being conducted through Continuing Studies there will be an additional $\$ 270$ per student fee to cover administrative expenses. In addition, each student will have to add in the cost of 4-credit hour course which is currently $\$ 708.20$. The total estimated cost per student is approximately $\$ 3100$. Furthermore, each student participating in the program must agree with the release (Appendix B)

"Proceedings of the 2005 American Society for Engineering Education Annual Conference \& Exposition Copyright ASEE 2005, American Society for Engineering Education" 
and budget/payment plan (Appendix C)

\begin{tabular}{lcr} 
& \multicolumn{2}{c}{$\begin{array}{c}\text { ECET MALAYSIA TRIP } \\
\text { SUMMER II 2005 }\end{array}$} \\
$\begin{array}{l}\text { Per Person Fees (based on 10 people) } \\
\text { 4 Credit Hour Trip }\end{array}$ & $\$$ & $2,090.00$ \\
\hline Cost of Trip & $\$$ & 275.00 \\
CS Processing Fees & $\$$ & 708.00 \\
Tuition & $\$$ & 5.00 \\
CS Registration Fee & $\$$ & 22.00 \\
Advertising & TOTAL & $\$$
\end{tabular}

\section{Conclusion}

This investigation is still ongoing in order to provide international experience for engineering technology students in a Malaysian summer study program. Daily progress is being made and anticipated study in Malaysia is scheduled from June $24^{\text {th }}$ through August $26^{\text {th }} 2005$. This paper addresses the thought process, reasoning and cost of implementing such a study abroad program. Upon the completion of the first round of students, future publication(s) will speak to the successes, failures and findings of internationally studying abroad in engineering technology.

(1) "Strengthening the US Government's Leadership in Promoting International Education" published by the US Department of Education on November 11, 2000

\section{GARY D. STEFFEN}

Gary currently serves as an Assistant Professor in the Electrical and Computer Engineering Technology at IPFW. Previously, he served 10 years as the Manager of Electronic and Computer Support specializing in computer networking. Gary received a Mater's degree from Ball State University in 2000 and recently completed the "Information and Security Assurance Certificate" at Purdue University sponsored by the NSA. His current areas of interest include local area networking, network security and wireless networking.

\section{ISKANDAR HACK}

Iskandar is an Associate Professor of Electrical and Computer Engineering Technology at Indiana-Purdue University Fort Wayne since 1984, and is an alumni of the ECET program at IPFW. He has worked over the years designing computer software, microprocessor and FPGA based embedded systems at Magnavox, General Electric, Navistar, Sensor Solutions and the Indiana Microelectronics Center on a consultant basis. 


\author{
Appendix A \\ MEMORANDUM OF UNDERSTANDING (MOU) \\ Between \\ Universiti Kuala Lumpur British Malaysian Institute (UniKL BMI) \\ Malaysia \\ And \\ Indiana University - Purdue, University Fort Wayne (IPFW) \\ United State of America
}

This Memorandum of Understanding (hereinafter after 'MOU') is made on the between

Academic Affairs Department, UniKL British Malaysian Institute, University Kuala Lumpur (hereinafter called UniKL BMI) and Indiana University - Purdue, University Fort Wayne (hereinafter called IPFW).

Following the discussions between the Academic Affairs Department, UniKL BMI and the Deaprtment of Electrical and Computing Engineering Technology, Indiana University - Purdue, University Fort Wayne (IPFW), the following programmes and activities have been agreed upon as specific areas for collaboration.

Article 1 - Introduction

1.1 This Memorandum of Understanding is the first agreement executed by the parties aims at increasing the cooperative and collaborative links between UniKL BMI and IPFW in order to enhance the scientific, technical and engineering competence and breadth of the two institutions; make better use of their respective facilities and increase opportunities of the faculty and staff of both institutions to collaborate on developing stronger programs of mutual interest and benefit.

1.2 That this goal will be accomplished through:

1.2.1 Exchange of researchers

1.2.2 Exchange of students

1.2.3 Exchange of scholarly and pedagogical materials

1.2.4 Joint research

1.2.5 Technical assistance and/or training

1.2.6 Other cooperative efforts as specified in ensuing separate Agreements.

Article 2 - Effective Date

2.1 This MOU will become effective on the date of signing for a period of _two (2)_ years and can be renewed by mutual consent. Both institutions have the right to initiate a termination of this linkage with at least six (6) months notice. This flexible position is recognized by both Institutions as necessary for harmonious working arrangement between tow Institutions which are geographically separated, and which have distinct and separate individual responsibilities.

2.2 That all specific projects to which this MOU may lead will be subject to the joint and periodic evaluation by the appropriate authorities of both universities.

Article 3 - Non-discrimination Policy

3.1 Both institutions are committed to the policy of non-discrimination against any person because of age, ancestry, colour, disability or handicap, national origin, race, religious creed or gender. Neither institution shall impose criteria for the exchange of scholars or students which would violate the principles of non-discrimination.

Article 4 - Authorizing Officer

4.1 The Dean of UniKL BMI and the _(post)_, Department of Electrical and Computing Engineering Technology, IPFW will have overall responsibility as the Coordinators for the effective operation and implementation of the MOU.

"Proceedings of the 2005 American Society for Engineering Education Annual Conference \& Exposition Copyright ASEE 2005, American Society for Engineering Education” 
4.2 Both institutions understand that this MOU cannot detail out how each collaborative project will be implemented, administered or funded. Both institutions acknowledge that they will need to enter into separate subsidiary agreements for each collaboration to address the scope of work; each institution's contributions and obligations to the project, the administration, coordination and implementation of the project, the respective rights of each party to own, use and license intellectual property that is developed in the course of the collaboration and other issues mutually agreed to by both Institutions.

4.3 Any researchers, lecturers and faculty of UniKL BMI and IPFW may initiate discussions on collaborative projects but only those persons authorized by the UniKL BMI and IPFW shall have authority to execute agreements committing their participation in particular collaborative projects.

Article 5 - Personnel

5.1 Each party shall be responsible for the selection and appointment of administrative and academic personnels it uses in support of this MOU and all cost associated therewith unless the parties enter into a written agreement for the joint appointment and support of such personnel on an equitable cost assignment basis.

5.2 Both Institutions are and shall remain independent contractors and nothing herein shall be construed to create a partnership, agency, joint venture or teaming agreement between both Institutions. Nothing herein hall be construed as implying that either Institution's employees are employee's of the other.

Article 6 - Amendments

6.1 Amendments to this MOU may be proposed, either by the undersigned or their successor, and shall become effective only if agreed to, in writing, by the undersigned or their successors.

Article 7 - General

7.1 This MOU is an agreement between UniKL BMI and IPFW and does not create or confer any right or benefit on any other party or person, private or public.

7.2 A determination that any term of this MOU is invalid for any reason shall not affect the validity of the remaining terms of the MOU.

\begin{tabular}{|c|c|}
\hline $\begin{array}{l}\text { INDIANA UNIVERSITY-PURDUE, } \\
\text { UNIVERSITY FORT WAYNE, USA }\end{array}$ & $\begin{array}{c}\text { UNIVERSITI KUALA LUMPUR } \\
\text { BRITISH MALAYSIAN INSTITUTE }\end{array}$ \\
\hline Signed by; & Signed by; \\
\hline $\begin{array}{l}\text { ASSOC. PROF. DR. ISKANDAR HACK } \\
\text { REPRESENTATIVE } \\
\text { ELECTRICAL \& \& COMPUTING } \\
\text { ENGINEERING TECHNOLOGY }\end{array}$ & $\begin{array}{lll}\text { DR. MOHD AMIR B. ABAS } & \text { MMN } \\
\text { DEAN } & & \\
\text { UNIKL } & \text { BRITISH } & \text { MALAYSIAN } \\
\text { INSTITUTE } & & \end{array}$ \\
\hline Witnessed by: & Witness by: \\
\hline $\begin{array}{l}\text { To Be Determined } \\
\text { IPFW }\end{array}$ & $\begin{array}{l}\text { DATO' SERI PROF. DR. IBRAHIM B. } \\
\text { SAAD } \\
\text { PRESIDENT / CHIEF EXECUTIVE } \\
\text { UNIVERSITI KUALA LUMPUR }\end{array}$ \\
\hline
\end{tabular}

"Proceedings of the 2005 American Society for Engineering Education Annual Conference \& Exposition Copyright ASEE 2005, American Society for Engineering Education" 


\title{
Appendix B
}

\section{Malaysia Trip \\ June 24 - August 26 \\ Release and Agreement}

\begin{abstract}
I (or parent or guardian if applicant is under 18), am an applicant for the Malaysia Trip 2005 provided by IPFW. By signing the Malaysia Trip application, I agree to the following:
\end{abstract}

1. I agree to release and forever discharge Indiana University Purdue University Fort Wayne(IPFW), its officers, trustees, faculty, employees and agents from any and all liability for all claims, demands or lawsuits whatsoever, for any loss, injury, or damage to myself or any other person, for the death of myself or any other person, to property of mine or any other person, or for any other loss, injury or damage whatsoever, as a result of any act or omission, including any negligence of IPFW or others which may be incurred in connection with the tour (including periods of supervised activity and periods of unsupervised activity), including but not limited to loss, injury or damages in connection with or related, directly or indirectly, to: (1) any accommodations, transportation or other services; (2) acts of God, dangers incident to the sea, fire, breakdown in machinery or equipment, acts of governments or other authorities (de jure or de facto), wars (declared or undeclared) hostilities, civil disturbances, strikes and riots; (3) thefts, pilferage, epidemics, quarantines, medical or customs regulations; (4) defaults, delays or cancellations of or changes in itineraries or schedules; or (5) as a result of any loss or damage resulting from any improper or insufficient passports, visas or other documents.

3. IPFW reserves the right to decline or retain any person as a tour participant should such person's health or mental condition or physical infirmity or general deportment or conduct, in the sole judgment of IPFW, impede the operation of the tour or the rights, welfare or enjoyment of other tour participants. In such event, a refund of any unused land tour services shall be the limit of IPFW or Purdue=s liability.

4. I agree to abide by IPFW' s regulations and the directions of any group leaders/tour directors associated with the tour. Failure to do so may result in my termination from the tour immediately. I understand that to disobey such rules or directions is to waive the right to a refund of any part of the program fee and that I may be sent home at my own expense.

5. I agree to abide by all local laws when abroad, including those concerning drugs and alcohol. (Minors must have parent's permission to use alcohol even if the local law would otherwise permit them to.) I understand that if I abuse or disobey such laws, I waive my right to a refund of any part of the program fee and that I may be sent home at my own expense. I also understand that should local authorities be involved, I will be subject to the laws of the country I am visiting.

6. IPFW has the right to make changes in the tour itinerary and to modify transportation arrangements if needed.

7. I understand that it is my responsibility to secure the necessary travel documents (passports and visas). Failure to obtain the necessary documents does not constitute grounds for a refund except according to the standard refund schedule. 


\section{Appendix C}

\section{Malaysia Trip \\ Payments \& Refunds}

By signing the Malaysia Trip application, I agree that I have read the following payment and refund information and agree to follow the payment and refund schedules outlined below:

\section{Payments:}

A $\$ 250$ deposit must be made by February 1, 2005

The deposit can be paid by personal check, money order, cash, Visa, MasterCard or Discover in the Division of Continuing Studies (Kettler Hall 145), 2101 E Coliseum Blvd., Fort Wayne, IN 46805.

Checks should be made payable to IPFW.

The balance of $\$ 2142$ is due by April 15, 2005.

The balance may be paid by the same methods mentioned above. You may pay the balance in installments if you wish, just so the full balance is paid by April 15.

\section{Refunds:}

If cancellation occurs before March 18, 2005, all monies will be refunded.

If cancellation occurs between March 19 - April 15, 2005 there will be a $\$ 150$ per person cancellation fee.

If cancellation occurs between April 16 -June 1, 2005 there will be a \$ 500 per person cancellation fee.

If cancellation occurs after June 1, 2003, payment is non-refundable. (Except in the case of serious illness, we will try to get as much as possible back for air and ground arrangements.)

All cancellations must be in writing.

\section{Credit:}

Students will also be required to register for ECET 499 during Summer Session II for a total of seven credit hours. Tuition for these credit hours will be billed through the IPFW bursar's office.

\section{What's included:}

Transportation to Kuala Lumpur from Indianapolis, Detroit, Chicago or Fort Wayne (gateway city to be determined based on availability and cost of airline tickets). Accommodations in residence halls at the University of Kuala Lumpur, ground travel and entrance fees for cultural experiences. Study abroad insurance coverage (including coverage for emergency medical treatment and transportation)

NOTE: Meals are not included in the cost of the trip. Meals can be eaten on campus for less than $\$ 12$ per day. However students may want to eat at other locations occasionally, which may decrease or increase the cost. Students should plan on allotting around $\$ 500$ for food. 